EGU2020-10052, updated on 29 Mar 2021

https://doi.org/10.5194/egusphere-egu2020-10052

EGU General Assembly 2020

(c) Author(s) 2021. This work is distributed under

the Creative Commons Attribution 4.0 License.

\title{
Correlation between Arctic river discharge and sea ice formation in Laptev Sea using sea surface salinity from SMOS satellite
}

\author{
Carolina Gabarro', Justino Martinez¹, Veronica Gonzalez-Gambau , Cristina González-Haro', \\ Estrella Olmedo ${ }^{1}$, Antonio Turiel ${ }^{1}$, Laurent Bertino ${ }^{2}$, Jiping Xie ${ }^{2}$, Roshin Raj ${ }^{2}$, Rafael Catany ${ }^{3}$, Manuel \\ Arias $^{3}$, Roberto Sabia ${ }^{4}$, and Diego Fernandez ${ }^{4}$ \\ ${ }^{1}$ BEC \& Institut de Ciències del Mar (CSIC), Barcelona, Spain (cgabarro@icm.csic.es) \\ ${ }^{2}$ Nansen Environmental and Remote Sensing Center, Bergen, Norway \\ ${ }^{3}$ Argans Ltd., Plymouth, United Kingdom \\ ${ }^{4}$ European Space Agency, ESA-ESRIN. Frascati, Italy
}

During the last 3 decades, the Arctic rivers have increased their discharge around 10\%, mainly due to the increase of the global atmospheric temperature. The increase of the river discharge carries higher loads of dissolved organic matter (DOM) and suspended matter (SM) entering to the Arctic Ocean. This results in increased absorption of solar energy in the mixed layer, which can potentially contribute to the general sea ice retreat. Observation based studies (e.g. Bauch et al., 2013) showed correlation between river water discharge and local sea ice melting on the Laptev sea shelf due to the change on the ocean heat. Previous studies are based with a limited number of observations, both in space and in time.

Thanks to the ESA SMOS (Soil Moisture and Ocean Salinity) and NASA SMAP (Soil Moisture Active Passive) missions we have daily the sea surface salinity (SSS) maps from the Arctic, which permit to observe the salinity variations due to the river discharges. The Arctic sea surface salinity products obtained from SMOS measurements have been improved considerable by the Barcelona Expert Center (BEC) team thanks to the project Arctic+Salinity, funded by ESA. The new version of the product (v3) covers the years from 2011 up to 2018, have a spatial resolution of 25km and are daily maps with 9 day averages. The Arctic+ SSS maps provide a better description of the salinity gradients and a better effective spatial resolution than the previous versions of the Arctic product, so the salinity fronts are better resolved. The quality assessment of the Arctic+SSS product is challenging because, in this region, there are scarce number of in-situ measurements.

The high effective spatial resolution of the Arctic+ SSS maps will permit to study for the first time scientific physical processes that occurs in the Arctic. We will explore if a correlation between the Lena and Ob rivers discharge with the sea ice melting and freeze up is observed with satellite data, as already stated with in-situ measurements by Bauch et al. 2013. Salinity and sea ice thickness maps from SMOS and sea ice concentration from OSISAF will be used in this study. 
Bauch, D.,Hölemann, J. , Nikulina, A. , Wegner, C., Janout, M., Timokhov, L. and Kassens, H. (2013): Correlation of river water and local sea-ice melting on the Laptev Sea shelf (Siberian Arctic), Journal of Geophysical Research C: Oceans, 118 (1), pp. 550-561 . doi: 10.1002/jgrc.20076 